UDK: $821.163 .41^{\prime} 255.4=111 ; 811.163 .41^{\prime} 371$

\title{
PREVODNA EKVIVALENTNOST NA NIVOU LEKSIČKIH OBRAZACA
}

\author{
VIOLETA STOJIČIĆ ${ }^{1}$ \\ Univerzitet u Nišu, Filozofski fakultet, \\ Odsek za anglistiku, \\ Niš, Srbija
}

U ovom radu prikazaćemo analizu uzorka paralelnih kolokacija preuzetih iz književnih dela na srpskom jeziku i njihovih prevoda na engleskom. Analizom želimo ukazati na moguća rešenja prevodnih zadataka u kolokacijskim okvirima, u smeru prevođenja sa srpskog jezika na engleski. Upoređivanjem izvornika i prevoda ispitaćemo kako je ostvarena ekvivalentnost na nivou leksičkih obrazaca onda kada je izborom leksema u prevodu obrazovana kolokacija koja prenosi sadržinu srpske kolokacije i ne narušava opsege kolociranja udruženih leksema. Paralelne kolokacije su i kongruentne jer pripadaju istom strukturnom tipu. Uz to, ekvivalentnosti radi, kolokacije u prevodu moraju činiti lekseme koje su u kolokacijskom smislu kompatibilne i koje ne narušavaju obrasce kolociranja i kolokacijska ograničenja jezika prevoda. Ne narušavaju ni semantičku prozodiju kao preferencu nekih leksema da kolociraju isključivo s leksemama pozitivnog ili negativnog značenja, što smo ispitali na uzorcima iz Britanskog nacionalnog korpusa.

Ključne reči: leksema, kolokacija, ekvivalentnost, kongruentnost, višeznačnost, ograničenja u kolociranju, semantička prozodija.

\section{LEKSIČKI OBRASCI U PREVOĐENJU}

Iako se u oblastima leksikoloških interesovanja pedagoške orijentacije iscrpno govori o kontrastiranju leksičkih obrazaca maternjeg i stranog jezika, u teoriji prevođenja ovom pitanju nije posvećena dovoljna pažnja, najverovatnije zbog sve manjeg zanimanja za mikrolingvističke zadatke prevodnog procesa. Smatramo da na sintagmatskom nivou leksički zadaci u prevođenju nisu zanemarljivi,jer podrazumevaju pronalaženje ekvivalenata kojima se ne bi samo očuvalo značenje izvornika, već bi se

1 Kontakt podaci (Email): vikis@eunet.rs 
poštovali obrasci udruživanja leksema, svi vidovi ograničenja u kolociranju i semantički potencijal leksičkog fonda jezika prevoda. U tom pogledu, Bejker (Baker 1992: 46) je, u vezi sa prevodnom ekvivalentnošću na nivou reči, naglasila da narušavanje obrazaca kolociranja pri prevođenju utiče i na prirodnost jezika prevoda i na značenje same kolokacije i poruke.

Što se same prevodne ekvivalentnosti tiče, prema Koleru (Koller 1989: 99-104), odnosi izvornika i prevoda mogli bi se preciznije utvrditi tako što bi se ograničavanjem na određeni okvir i uslove doneo sud koji glasi: „Između izvornog teksta i prevoda postoji ekvivalentnost ako prevod ispunjava određene zahteve u odnosu na postojeće uslove". Prema uslovima koji određuju ekvivalentnost, Koler razlikuje (a) denotativnu ekvivalentnost, uslovljenu značenjem teksta, (b) konotativnu ekvivalentnost, uslovljenu izborom reči, (c) tekstualno-normativnu ekvivalentnost, uslovljenu normama jezika ili vrstom teksta, (d) pragmatičku ekvivalentnost, uslovljenu vanjezičkim faktorima i (e) formalnu ekvivalentnost, kojom se čuvaju formalno-estetske karakteristike izvornika izražene stilskim sredstvima. U prevođenju kolokacija smatramo da su jednako važni svi pomenuti aspekti, i to (a) značenje rečenice kao iskaza u kome se kolokacije javljaju, (b) izbor reči koji je neposredan kontekst u kome se realizuje leksičko značenje, (c) vrsta teksta koja je u ispitanom slučaju književna, sa svojom ekspresivnom funkcijom, koja bliže uslovljava izbor reči, (d) situacioni kontekst okolnosti i zbivanja na koje se odnosi iskaz u kome se kolokacija javlja i (e) umetnički stil kazivanja u književnosti, koji se odvaja od razgovornog jezika po svom leksičkom bogatstvu.

Ovde ćemo ekvivalentnost sagledati kao odnos između kolokacija iz srpskih izvornika, i to književnih tekstova, i njihovih prevoda na engleskom. Ekvivalentnost smo utvrdili na osnovu jednakosti sadržine, ali i na osnovu toga da li su engleske kolokacije ostvarive u tom jeziku, tj. da li one narušavaju kolokacijski i semantički potencijal udruženih leksema. U ispitanom uzorku, ekvivalentnost, dakle istovetnost sadržine, potvrdili smo uglavnom kod strukturno podudarnih srpskih i engleskih kolokacija, u datim uslovima konteksta, a bez obzira na to da li lekseme u kolokaciji iz prevoda u izolaciji imaju jednake komponente značenja kao odgovarajuće lekseme kolokacije iz izvornika. Pod ekvivalentnošću na nivou kolokacija podrazumevamo odnos jednakosti ili približne jednakosti u sadržini između dveju kolokacija iz izvornika i prevoda, koja $u$ idealnom slučaju podrazumeva i jednakost ili približnu jednakost $u$ formi i funkciji (Stojičić 2009: 149). Sadržinom su ovde obuhvaćena semantička svojstva kolokacija, dok se forma odnosi na morfosintaksička svojstva kolokata. Funkcija je shvaćena dvojako - kao sintaksička funkcija, u vezi sa funkcijama koje lekseme mogu ostvariti u rečenici, i kao sociološka funkcija, u odnosu na ulogu jezika u određenom kontekstu ili registru.

Na početku možemo pomenuti da smo pri obradi koprusa ustanovili i odnos delimične ekvivalentnosti kod određenih parova kolokacija, kojom se ovde nismo bavili, ali ćemo je pomenuti kao suprotnost potpunoj ekvivalentnosti za koju se zanimamo. Delimična ekvivalenost ispoljava se onda kada srpski i engleski kolokati nisu podudarni u nekim komponentama značenja, ili je posredi narušavanje opsega kolociranja jedne od odabranih leksema u jeziku prevoda, kakav je sledeći slučaj:

Ulica je brujala od ljudskih glasova, ali je to bio tmuran bruj, iz kojeg bi povremeno iskakala neka rečili grupa reči. 
The street was humming with human voices, but it was a despondent hum, out of which at times a word or group of words would break.

(Velmar-Janković 1991; 2002)

Pridev despondent [verY unHappy] se udružuje isključivo $s$ imenicama za ljude $u$ engleskom jeziku, i opisuje emotivno stanje, pa je ovde narušen njegov opseg, i samim tim nije ponuđena kolokacija ekvivalentne sadržine. Ekvivalentni pridevu tmuran [NEVESEO] ovde bi bili pridevi grave [FULL OF SORROW], sullen [OF A DULL, MOURNFUL TONE] i sombre [OF A DULL, MOURNFUL TONE], sudeći prema njihovom značenju, kao i prema imenicama s kojima se udružuju u upotrebi jezika.

Što se potpune ekvivalentnosti tiče, tumačenje interakcije značenja udruženih leksema u izvorniku kojom se ostvaruje sadržina date kolokacije omogućava dosledno prenošenje te sadržine najezik prevoda.Stimu vezi, primetilismo da engleske kolokacije kojima je ostvarena ekvivalentnost ukazuju i na to da je kolokacija iz izvornika valjano shvaćena pošto je valjano protumačena interakcija značenja leksema u toj kolokaciji, što je omogućilo pronalaženje odgovarajućeg ekvivalenta, kao u sledećem primeru:

Noć provede u retkom snu, iscepanom brigama, razočaranjima, kajanjima.

The King spent the night in a fitful sleep broken by anxieties, disappointments and regrets.

U kolokaciji redak san pridevski kolokat se ne bi doveo u vezu ni sa jednim od značenja koje u srpskom jeziku ostvaruje, i to [NE GUST] i [NE ČEST]. Njegovo tumačenje zavisi od imeničkog kolokata, koji je imenica sa značenjem 'psihološko stanje/proces'. Navedeni kolokat ne bi se mogao opisati prvonavedenom sememom, u čijem su opsegu zastupljene imenice za denotate određene gustine. Što se druge sememe tiče, ona se isključuje zbog zahteva šireg konteksta, ovde konteksta rečenice, u kojoj se navodi da je taj san isprekidan, a ne povremen, što upravo kazuje engleski pridev fitful. Štaviše, sudeći prema situacionom kontekstu, imenicu san ne bi trebalo shvatiti kao snevanje onda kada joj je engleski ekvivalent imenica dream, već kao spavanje, zbog čega je u prevodu i upotrebljena imenica sleep. Sadržina srpske kolokacije jeste [IIPREKIDANo SPAVANiE], te joj je, u tom pogledu, potpuno ekvivalentna ostvarena engleska kolokacija.

Najneposredniji kontekst $u$ kome se $u$ jeziku ostvaruju tesne značenjske veze leksema jeste rečenica, u kojoj se mogu ustanoviti dodatne informacije o značenju udruženih leksema, što dalje usmerava pronalaženje ekvivalenata, kao u sledećim paralelnim rečenicama:

Tvojim pričama o Vilinom Konjicu. Prvom kojom si je zagolicao, drugima kojima si hteo da ugasiš plamen.

By all that silly talk of yours about a "Mayfly" he told himself, bitterly, the first time he called Mitia that, doing so to awake Anna's interest, then going on playing with the comparison in an attempt to quench the flame.

(Davičo 1952; 1959) 
Iz konteksta srpske rečenice, može se zaključiti da se radi o pripovedanjima u kojima lik o kome je reč na sagovornika ostavlja određeni utisak, što kazuje glagol zagolicati. Zbog toga je imenica plamen protumačena u svom prenesenom značenju - kao jaka želja, što je i preneseno značenje engleske imenice flame. Celokupna kolokacija može se shvatiti kao zadovoljenje ili potiskivanje te želje, odslikano kao gašenje plamena. Iz tog razloga se u engleskom jeziku ne bi odabrao glagol douse, koji učestalo kolocira $s$ imenicom flame, ali samo u doslovnom značenju [ExtinguisH BY POURING WATER]. Glagol quench u engleskom jeziku ima preneseno značenje [suPPREsS/ SATISFY], u kome se udružuje s imenicama za označavanje snažnih emocija, kakve su longing, rage i lust. Prema tome, srpska i engleska kolokacija su ekvivalentne, budući da se kolokacijom u prevodu čuva sadržina srpske kolokacije i poštuje opseg kolociranja zastupljenih leksema, pri čemu su pojedinačni kolokati obeju kolokacija podudarni u komponentama prenesenog značenja.

Ekvivalentnost na nivou kolokacija se retko ostvaruje postupkom prevođenja rečza-reč (engl. word-for-word), ili, mogli bismo reći, leksema-za-leksemu, koji shvatamo kao postupak u kome se svaka leksema iz izvorne kolokacije prevodi najbližim rečničkim ekvivalentom u jeziku prevoda. Takav postupak najčešće dovodi do grešaka u obrazovanju kolokacija u stranom jeziku, jer se ekvivalenti biraju bez pozivanja na uži jezički kontekst i ograničenja u kolociranju. Njumark (Newmark 1988: 285) ističe da se smisao u prevodu može narušiti onda kada je tekst prevoda rezultat automatski prihvaćenih rečničkih značenja, pa u slučaju prevođenja isključivo u skladu s rečnikom može doći do semantičkog gubitka. Razmotrićemo sledeći primer:

Zavese na prozorima se zanjihaše, u dvorištu stari orah jeknu od udara vetra. The curtain billowed before the windows, and the old walnut tree in the courtyard creaked in the wind.

Za glagol njihati se izolovani rečnički ekvivalenti u engleskom jeziku su swing, rock i sway. Sva tri glagola imaju suštinsko značenje [MOVE FROM SIDE TO SIDE/FORWARDS AND BACKWARDS]. Njihovi semantički opsezi obuhvataju imenice za označavanje predmeta i ljudi. Svaki od ovih glagola ima i dodatne značenjske komponente, zbog čega im se opsezi razlikuju: glagol swing podrazumeva komponentu [REPEATEDLY AND REGULARLY FROM A FIXED POINT] (npr. leg (of a table) swings), glagol rock komponentu [sLowly AND REGULARLI] (npr. boat rocks), a glagol sway komponentu [LEAN sLowly] (npr. tree sways). Nijedno od tri značenja ne odgovara radnji koja bi se pripisala entitetu kakav je zavesa, koju ne odlikuje ritmično i snažno kretanje, niti odgovara kontekstu navedene rečenice, iz koje se jasno vidi da se kretanje odvija pod uticajem vetra. Zato je odabrani glagol billow [SWELL OUT AND MOVE SLOWLY IN THEWIND] odgovarajući, jer njegovu upotrebu direktno uslovljavaju komponente značenja lekseme curtain.

Još jedna pojava koja je važan faktor u prevođenju kolokacija jeste višeznačnost, pod kojom podrazumevamo svojstvo lekseme da istom formom ostvaruje više od jedne sadržine, odnosno sememe, koje se konkretizuju u užem kontekstu, kakav je kolokacija. Ovde želimo pomenuti da višeznačne lekseme imaju onoliko opsega kolociranja koliko i semema, pre nego jedan širok, objedinjeni opseg kolociranja. Može se pretpostaviti da lekseme koje, pored doslovnog, imaju i preneseno značenje moraju imati zasebne 
opsege, jedan za doslovno, a drugi upravo za preneseno značenje, te u tim značenjima obrazuju sasvim drugačije kolokacije. Ova pojava se najjednostavnije može prikazati kroz prideve, i to one koji u doslovnom značenju opisuju fizičke odlike materije, kakvi su recimo pridevi thick i hot, u kolokacijama thick wall i hot oil, dok se u prenesenom značenju dovode u vezu sa apstraktnim pojmovima, npr. thick [sтrong] accent i hot [POPULAR] topic. U srpskom, takvi pridevi su baršunast, sa doslovnim značenjem u kolokaciji baršunasta [OD BARŠuna] tkanina, a sa prenesenim značenjem [NEŽAN], u sprezi sa imenicom glas, ili pridev krilat u značenju [kojI IMA KRILA], npr. krilati konj, i u prenesenom značenju [PUN POLETA], u kolokaciji krilata duša (RMS 1990).

Stoga, pri prevođenju na leksičkom nivou podrobnije se moraju razmotriti opsezi kolociranja višeznačnih leksema, koji se obrazuju za svaku od njihovih semema zasebno. Kolokacije su u suštini obrasci udruženih semema, te bi adekvatan postupak u prevođenju kolokacija mogao biti semema-za-sememu, naročito kod višeznačnih leksema koje u kolokacijama učestvuju sa jednim od svojih značenja koje se precizira u sprezi sa drugom leksemom. Na primerima iz korpusa može se prikazati kako se kod višeznačnih srpskih leksema u procesu prevođenja valjano procenilo koja od semema učestvuje u upotrebljenoj kolokaciji, te se prema tome pronašao i engleski ekvivalent:

Zaista je podla bila ta potreba da prigušim svoj smeh, gotovo napad smeha, nad našim nesporazumom.

Really, there was something base about my need to suppress my laughter, a fit of laughter at our misunderstanding.

(Velmar-Janković 1991; 2002)

Srpski glagol prigušiti ima doslovno značenje [UdAviti GušENJEM]. Očigledno je da se u navedenoj kolokaciji prigušiti smeh radi o prenesenom značenju [SPRĚ̌ITI DA SE POKAŽE u PUNOJ MERI], tj. u pitanju je potiskivanje emotivne reakcije, pa se ekvivalent odabrao upravo prema tom značenju, i to glagol suppress [NOT EXPRESS FEELINGS OR REACTIONS], a ne glagoli strangle ili choke.

Beč je nameran da sa vama sve sporove reši na bojnom polju.

Vienna is determined to settle all disputes with you on the battlefield.

(Ćosić 1978; 1981)

U kolokaciji rešiti spor, glagol rešiti učestvuje sa značenjem [oKončatı/ODREDITI ISHOD], a ne sa značenjem [Dati PRAVILAN ODGovor] (rešiti zadatak/zagonetku - solve a problem/ riddle) ili [озLоводіт]] (osloboditi muka - deliver from pain), te mu je ekvivalentan glagol settle [RESOLvE/END], koji u engleskom jeziku upravo u tom značenju učestalo kolocira sa imenicom dispute.

\section{ANALIZA UZORKA}

(1) U sumraku bi, kao onda u vozu, i kao pod strehom magacina pokojnika, svetlucala njegova cigareta ... 
His cigarette would glimmer in the dusk, as it had on the train, under the eaves of the Warehouse of the Dead.

Glagol svetluca upućuje na to da predmet emituje vrlo slabu svetlost, te on stoji prema osnovi svetleti u deminutivnom odnosu. Ovo značenje je očuvano engleskim glagolom glimmer [shine FAINTıY], koji prenosi iterativno značenje srpskog glagola, jer ukazuje na to da je svetlo sporadično, po čemu se razlikuje od glagola glow [PRODUCE STEAdY LIGHT].

(2) I ćuti sve dok ne zagrme topovi na Savi i Dunavu.

If only he could say nothing until the artillery started to thunder on the Sava and the Danube.

(Ćosić 1978; 1981)

Opseg glagola thunder obuhvata imenice kao što su horse / sea / truck, jer je reč o proizvođenju zvuka sličnog grmljavini. To je karakteristično i za srpski glagol grmeti, čijim su opsegom obuhvaćene imenice motor / avion / aplauz.

(3) Nad njim šište granate i padaju okolo. Množe se i rastu požari, zjape rupčage, razjapljuju se krovovi.

There shells were whistling, fires raging, roofs blowing wide open, holes gaping.

Kao ekvivalenti srpskog glagola ne bi se prihvatili, recimo, glagoli hiss, whizz i whoosh, koji bi se mogli, van konteksta, utvrditi kao rečnički ekvivalenti. Razlog leži u tome što se u srpskoj rečenici priloškom konstrukcijom nad njim pokazuje i kretanje onoga što proizvodi odgovarajući zvuk. Glagol hiss ne pokazuje kretanje onoga što proizvodi šištanje. Glagole whizz i whoosh ovde bismo izuzeli zbog njihove neformalne upotrebe. Glagol whistle [PRODUCE A SHRILL SOUND BY RAPID MOVEMENT] upravo ukazuje na kretanje denotata date imenice, kao i na prodoran zvuk fijukanja koji on pri kretanju proizvodi.

(4) Pazite da ovaj mali neprijatelj ne pomrači slavu i ne kompromituje dosadašnje uspehe slavne nemačke vojske.

Make sure that this small enemy does not dim the fame or compromise the success of the glorious German army.

(Ćosić 1978; 1981)

Glagol pomračiti ima preneseno značenje [umanjiti]. U engleskom jeziku, glagol dim se u prenesenom značenju [MAKE BECOME LESS STRONG] udružuje s apstraktnim imenicama, i to pozitivnog značenja, kakve su happiness, hope, prospect, među kojima je i imenica fame.

(5) Jer se od krsnog straha ne sme vratiti u knjigu, pa čini čuda i pokore. It fears the cross and, not daring to go back into the book, it wreaks havoc all around. 
Činiti pokor ukazuje na nanošenje štete i uništenje, i po toj sadržini joj odgovara upotrebljena engleska kolokacija. Engleski glagol je višeznačan, a ovde je zastupljen u značenju [CAUSE/EFFEcT], koje je opšte, a precizira ga data imenica. Uglavnom se udružuje $\mathrm{s}$ imenicama negativnog značenja (vengeance, damage, harm), a najčešće upravo $\mathrm{s}$ imenicom havoc, s kojom ostvaruje kolokaciju sa sadržinom [DESToRY].

(6) "Imaojemnogo žena", kažejedna verzija ove legende objavljena u Veneciji 1772. godine na srpskom jeziku, ,"i želeći da ima žene svih vera, ne samo što se klanjao raznim idolima nego je zbog svoje sklonosti prema ženama i naložnicama hteo i sam da ispoveda razne vere."

"He had many women", says a version of this legend published in Venice in 1772 in the Serbian language, "and, wanting to have women of all faiths, he not only worshipped various idols, but out of affection for women and mistresses, also wanted to profess different faiths."

(Pavić 1990; 1996)

Ovde je ispovedanje vere predstavljeno kao javno iskazivanje verskog ubeđenja, što je kazano engleskim glagolom profess [DECLARE OPENLY]. U sličnom značenju mogao bi se upotrebiti i glagol practise, ali se njime pokazuje samo poštovanje religijskih običaja, a ne i izjašnjavanje o veri.

(7) Ne govori o svojem snu svojoj braći! Jer će skovati zaveru protiv tebe. "Speak not of your dream to your brothers! They will hatch a plot against you."

(Pavić 1990; 1996)

U svom prenesenom značenju glagol hatch ograničenog je opsega, jer se isključivo udružuje s imenicom plot, s kojom realizuje značenje [DEvISE AND DEVELoP]. Uz to, ovaj glagol se odlikuje i negativnom prozodijom, jer data imenica označava negativnu pojavu. Čini se da je negativna prozodija karakteristična i za srpski glagol skovati, koji se u značenju [smisLiti] udružuje s imenicama laž, zavera i urota.

(8) Pošto se odnosilo na Al Safera, izazvala je kaganovu ljubomoru i gnev. Since it referred to Al-Safer, it aroused jealousy and anger in the kaghan. (Pavić 1990; 1996)

U srpskim kolokacijama radi se o pobuđivanju ljubomore i gneva. Ovde kao ekvivalent glagolu izazvati ne bismo u obzir uzeli engleski glagol cause [MAKE SOMETHing HAPPEN], jer njegov opseg obuhvata imenice za označavanje događaja. Odgovarajući glagol je upravo glagol arouse [MAKE SOMEBODY EXPERIENCE A PARTICULAR FEELING OR HAVE A REACTION/ ATTITUDE], koji kolocira isključivo s imenicama za osećanja. Sličnog značenja su i glagoli inspire i awaken, ali on i imaju pozitivnu prozodiju (inspire confidence / creativity; awaken interest / enthusiasm), pa se ne bi udružili s imenicama jealousy i anger.

(9) Jadna ti je to nada da mi pod paljbom trista topova slučajno ni jedan geler neće raspolutiti glavu i da me od kiše kuršuma ni jedan neće probušiti. 
It's poor hope that under a salvo of three hundred guns not a single splinter will split my head open, and that in a rain of bullets not one will hit me.

(Ćosić 1978; 1981)

U srpskoj kolokaciji, krozznačenje prvog kolokata (kiša) istaknutje vid u kome se denotat drugog kolokata (metak) pojavljuje, i ova je imenica upotrebljena slikovito, kao velika količina nečega što pada. Imenica rain u značenju [A LARGE NUMBER OF THINGS MOVING THROUGH THE AIR AND FALING Down] udružuje se upravo s imenicom bullets, i s imenicama arrows, missiles, shells.

(10) Još ga je držala ona uplašena, revoltirana srdžba i on je uvređen pisao brzo, bez kolebanja i brisanja kao mamuzan pritiscima gneva što je pario u njemu, nadimajući mu teški grudni koš.

He was still fuming with outraged indignation, and in his wounded pride wrote fast, without hesitation, never crossing out - as if those stabs of rage which rent him till his broad, deep chest heaved were spurs to his pen.

(Ćosić 1978; 1981)

Pritisci gneva su jaki osećaji gneva. U poetskom jeziku, iznenadna negativna osećanja se u engleskom jeziku opisuju imenicom stab, kojom se, aluzijom na fizički bol, slikovito prikazuje način na koji se ta osećanja proživljavaju. Ova imenica ima negativnu prozodiju, i najčešće je udružena s imenicama pain i doubt.

(11) Hajduk je imao grozničavu potrebu da govori, kao da time produžava vek, a Živan je hteo da pokaže svoju silu i brani svoj ugled pred društvom, $i$ ko zna dokle bi se njih dvojica tako objašnjavali da ih komandir nije prekinuo.

The bandit had a fevered need to talk and mark time, while Živan wanted to assert his authority and buttress his reputation before the company, and who knows how long the two of them might have dickered in this fashion if the commandant had not interrupted them.

(Andrić 1962; 1986)

Srpski i engleski pridevi grozničav i fevered derivati su imenica groznica i fever, pojedinačno, ali imaju preneseno značenje [užurBAN/NESTRPLJV] i [STIRRED BY STRONG EMOTION]. U tom značenju se udružuju s apstraktnim imenicama za emocije i kognitivne procese, u srpskom jeziku recimo s imenicama nemir i napor, a u engleskom, s imenicama imagination i excitement.

(12) Upravo kadje to naređivao-biloje mirno jutro pred kraj leta - donesoše mu molbu jednog mladog a učenog carigradskog mualima, koji je bio iz Bosne rodom, pisao vrlo glatke stihove, $i$ koga je vezir s vremena na vreme darivao i pomagao.

Just as he was issuing these instructions - it was a fine morning in late summer they brought him a petition from a young and learned teacher of the Koran who was Bosnian by birth, and author of some polished verses, whom the Vezier had patronized and helped on past occasions. 
Pridev gladak u spoju s imenicama stih ili rečenica jeste pozitivna ocena elegantnosti jezika. Engleski pridev polished ima značenje [OF REFInED languaGE], te je ekvivalentan datom srpskom pridevu.

(13) Seti se Natalije, zagleda mu se u oči, krupne, žarke, sa oštrim usecima na bledom mršavom licu koji su joj se od prvog viđenja dopali, zažele da ih pomiluje vrhovima prstiju, upita ...

She thought of Natalia as she gazed into his burning eyes and at the deep contours of the thin, pale face she had liked from the moment she saw it.

(Ćosić 1978; 1981)

Naspram drugih prideva sličnog značenja koji bi mogli biti udruženi s imenicama oči i eyes, kakav je pridev sjajan (sjajne oči) u srpskom jeziku i bright u engleskom, pridevi žarke i burning su izražajniji, jer ukazuju i na intenzitet osećanja koji je u opisanim oklonostima izražen pogledom. Osim toga, upoređene kolokacije su ekvivalentne u stilskom pogledu, jer su obe karakteristične za jezik književnosti.

(14) Nad njima isto tako jake maštarije i osećanja, šta li. And with them came rich fantasies and feelings.

(Pavić 1998; 1998)

Pridev jak se uz datu imenicu tumači kao bogat slikama i iluzijama, pa se kao ekvivalentan ne bi prihvatio engleski pridev strong, jer se u kolokaciji ukazuje na upečatljivost sanjarenja, a ne na bilo kakvu snagu. Engleski pridev rich kolocira s apstraktnim imenicama da pokaže upečatljivost označene pojave, kakve su imenice sense i experience.

(15) On prelete pogledom preko njenog sparušenog lica, izgriženog crvenim mrljama očiju i opet se okrenu dvorištu.

He flashed a glance over her shriveled face, at the bitten-out patches of her eyes, then back at the yard.

(Davičo 1952; 1959)

Engleski pridev u značenju [DRY out/Form WRINKLEs] udružuje se s imenicama za biljke ili delove biljaka (tree, branch, plant, leaf), ali i s imenicama face i skin. S obzirom na značenje i upotrebu srpskog prideva sparušen [uveo/Isušen], može se tvrditi da se njihovi opsezi u potpunosti poklapaju, pa su i kolokacije ekvivalentne.

(16) Ne, nije to bila samo njena lepota, njeno pokretljivo, neiščašivo telo, taj snežni vulkan u stalnoj erupciji, ta divlja mačka njene slatke puti, njene razularene čelične, savitljive snage tako slične slabosti lomnijoj od travke.

No, it was not merely her beauty, her mobile, little body, that snowy volcano in constant eruption, that wildcat quality of her sweet flesh, that glowing steel, that lissom torso so suggestive of a weakness greater than that of a mere blade of grass.

(Davičo 1952; 1959) 
Imenica snaga se u srpskom jeziku katkad upotrebljava u prenesenom značenju [Teı0] (prema RMS 1990), te je engleska imenica torso adekvatna. Pridevu savitljiv [GiBak] odgovara engleski pridev lissom [FLEXiBlE] koji je redak u savremenom engleskom jeziku, i u Britanskom nacionalnom korpusu registrovan je u malobrojnim kolokacijama s imenicama body i figure.

\section{ZAKLJUČAK}

Na uzorku paralelnih rečenica u kojima su sadržane kolokacije iz srpskih književnih tekstova i njihovih engleskih prevoda kvalitativnom anlizom smo ispitali leksička sredstva kojima je ostvarena ekvivalentnost na kolokacijskom nivou. Ekvivalentnost smo utvrdili kod onih parova kod kojih je engleska kolokacija očuvala značenje srpske kolokacije, kada je sa njom podudarna po sadržini, pri čemu je jednako važno to što su odabrane udružene engleske lekseme poštovale sledeće parametre kolokabilnosti:

(a) semantička ograničenja u kolociranju, što su zapreke nametnute semantičkim svojstvima leksema;

(b) opseg kolociranja, koji obuhvata lekseme s kojima se data leksema, poštujući ograničenja u kolociranju, najčešće udružuje ili s kojima se može udružiti u upotrebi jezika; $i$

3) semantičku prozodiju, što je propratna pojava u kolociranju koja se manifestuje u težnji nekih leksema da budu udružene s leksemama za entitete, pojave ili radnje pozitivnih ili negativnih karakteristika (v. Louw 1993).

Uz to, kolokacije koje smo ispitali jesu i kongruentne, jer su podudarne po formi, budući da imaju jednaku strukturu, odnosno kolokati kolokacije u izvorniku i kolokacije u prevodu pripadaju istoj vrsti reči. Strukture koje preovlađuju u uzorku su imenica + glagol, glagol + imenica i pridev + imenica.

Prikazanu analizu prevodne ekvivalentnosti srpskih i engleskih kolokacija orijentisali smo ka objašnjenju sadržinskih podudarnosti, a ne ka uspostavljanju direktnih veza jednakosti između kolokacija niti ka formiranju spremnog i opštevažećeg popisa identičnih kolokacija dvaju jezika. Analiza prevodnog korpusa se tiče jezičke performanse u stvaralačkom postupku kao što je prevođenje, a kolokacije su predstavljale težište ispitivanja odluka u uspostavljanju ekvivalentnih sadržinskih relacija između prevodnih jedinica.

Sličnosti i razlike koje na leksičkom nivou postoje između jezika, kako u celokupnim leksičkim fondovima, takoi u kolokacijskim potencijalima svake lekseme zasebno, imaju uticaja na izbor i odlučivanje u toku prevođenja na nivou reči. Kod kolokacija, leksička analiza iz koje se sagledava prevodni zadatak mora se zasnivati na sintagmatskoj perspektivi, jer pronalaženje odgovarajućeg prevodnog ekvivalenta jedne lekseme iz izvornika u velikoj meri zavisi od jezičkog konteksta koji, u kolokacijskom pogledu, čine druge lekseme. Pristupajući rešavanju leksičkih problema pri prevođenju ne treba imati u vidu reči van konteksta jer bi takvo prevođenje bilo pogrešno - bilo bi zasnovano samo na pronalaženju leksikografski ustanovljenih dvojezičnih parova. Treba se, dakle, usredsrediti na najmanje sintagmatske strukture u kojima reči realizuju svoje značenje, kakve su kolokacije. 
Što se tiče smernica u prevođenju kolokacija u opštem smislu, ovde su značajne dve pretpostavke: 1) kolokacije nisu predvidive na osnovu standardnih gramatičkih pravila jednog jezika i2) obrasci udruživanja leksema u jeziku izvornika mogu se bitno razlikovati od obrazaca u jeziku prevoda. Uže posmatrano, pokazalo se da u prevođenju na nivou reči, gde se podrazumeva poštovanje gramatičkih i sintaksičkih normi sistema jezika prevoda, u vidu treba imati nekoliko činilaca. Prvo, leksičku analizu treba najpre sprovesti na samom izvorniku, kako bi se u njegovom sklopu protumačile kolokacijske veze između upotrebljenih leksema. Uspostavljanje ekvivalentnosti između kolokacija započinje identifikacijom i interpretacijom kolokacija u izvorniku. Tumačenjem sadržine kolokacija u izvorniku precizno se određuje smisao udruženih leksema, što je put do adekvatnog prevoda na leksičkom nivou, pošto se upravo u kolokacijama značenje reči ostvaruje i precizira. Ekvivalentnost na nivou kolokacija počiva na očuvanju semema koje učestvuju u kolokaciji, a njihova interakcija, koja ostvaruje sadržinu kolokacije, odlučujući je faktor u pronalaženju ekvivalentnih kolokacija u jeziku prevoda. Ovo je posebno važno kod višeznačnih leksema, koje u kolokaciji kao najužem leksičkom kontekstu ostvaruju jedno od svojih značenja.

Drugo, obrazovanje kolokacija je osobenost svakog jezika pojedinačno i na tom nivou ekvivalenti ne mogu uvek biti ustanovljeni postupkom reč-za-reč. Tumačenjem sadržine kolokacije u izvorniku treba ustanoviti kojim bi se leksemama, preciznije sememama, u jeziku prevoda ostvarila kolokacija iste sadržine kojom se čuva nameravano značenje izvornika. Ekvivalentna kolokacija utvrđuje se pravilnim izborom kolokata u zavisnosti od sadržine kolokacije iz izvornika, a ne od doslovnog značenja njenih kolokata, pa se sadržina izvorne kolokacije može na jeziku prevoda iskazati odabirom reči drugačijih semantičkih svojstava. Sve u svemu, intuitivno rešenje ili doslovan prevod mogli bi dovesti do obrazovanja kolokacije koja nije po sadržini verna kolokaciji iz izvornika i/ili narušava opseg kolociranja makar jedne od udruženih leksema iz jezika prevoda. Konačno, kolokacija se odlikuje semantičkom i strukturnom celovitošću, a njen ekvivalent je u idealnom slučaju kolokacija istih sadržinskih i formalnih svojstava.

Istraživanjima u okviru prevođenja kolokacija može se pokazati da se leksički nivo dodiruje sa drugim jezičkim nivoima. Dodiruje se sa semantičkim nivoom preko denotacije i konotacije udruženih leksema, dakle preko njihovih semantičkih svojstava, od kojih je višeznačnost presudan faktor. Kolokaciju treba tumačiti kao sadržinski celovit segment, i u vidu treba imati sememe koje u ostvarivanju te sadržine učestvuju. Ako je tu celovitost u prevodu moguće ostvariti takođe kolokacijom, ekvivalentan spoj treba da sačinjavaju lekseme čija smisaona interakcija prenosi sadržinu kolokacije iz izvornika i u jeziku prevoda poštuje uslove kolociranja. U pogledu stila, u prevodu treba razmotriti i asocijacije udruženih leksema, jer ekspresivnu vrednost književnih slika treba očuvati u književnom prevođenju. Na kraju, na pragmatičkom nivou, uticajan faktor je i komunikacijska vrednost upotrebljene kolokacije u iskazu koji određuju i vanjezički faktori, opisani entiteti i događaji, i poruka pisca. U tom smislu, pri prevođenju treba uzeti u obzir kolokaciju upotrebljenu u konkretnoj komunikacionoj situaciji koja utiče na utvrđivanje ekvivalenta koji bi dosledno odgovarao datim situacionim uslovima. 


\section{LITERATURA}

Baker, M. 1992. In Other Words: A Coursebook on Translation. London: Routledge.

Koller, W. 1989. Equivalence in translation theory. In A. Chesterman (ed.) Readings in Translation Theory. Helsinki: Finn Lectura, 99-104.

Louw, B. 1993. "Irony in the text or insincerity in the writer? The diagnostic potential of semantic prosodies". In M. Baker, G. Francis and E. Tognini-Bonelli (eds.) Text and Technology. In Honour of John Sinclair. Philadelphia/Amsterdam: John Benjamins. Newmark, P. 1988. A Textbook of Translation. Hertfordshire: Prentice Hall Europe. Stojičić, V. 2009. Kolokacije u književnom prevođenju sa srpskog jezika na engleski. Neobjavljena doktorska disertacija, Filozofski fakultet, Novi Sad.

\section{REČNICI}

Rečnik srpskohrvatskoga književnog jezika (RMS). 1990. Drugo fototipsko izdanje. Novi Sad: Matica srpska.

\section{KORPUS}

Britanski nacionalni korpus (The British National Corpus). 2007. 0xford University Computing Services, BNC Consortium. [Internet]. Dostupno na: http://www. natcorp.ox.ac.uk/ [21.11.2010].

\section{KNJIŽEVNI KORPUS}

Andrić, I. 1962. Žena na kamenu. Beograd: Nolit.

Andrić, I. 1986. The Pasha's Concubine and Other Tales, prev. J. Hitrec. Sarajevo: Svjetlost. Cosić, D. 1978. Vreme smrti IV. Rijeka: Otokar Keršovani.

Ćosić, D. 1981. South to Destiny, prev. M. Heppell. New York/London: Harcourt Brace Jovanovich Publishers.

Davičo, 0. 1952. Pesma. Beograd: Novo pokolenje.

Davičo, 0. 1959. The Poem, prev. A. Brown. London: Lincolns Prager Publishers Ltd.

Pavić, M. 1990. Hazarski rečnik. Beograd: Prosveta.

Pavić, M. 1996. Dictionary of the Khazars, prev. Ch. Pribićević-Zorić. Beograd: Dereta.

Pavić, M. 1998. Damaskin. Priča za kompjuter i šestar. [Internet]. Dostupno na: http:// ezone.org/damaskin/ [08.06.2006].

Pavić, M. 1998. Damascene. A Tale for Computer and Compasses, prev. Sh. Sofrenović.

[Internet]. Dostupno na: http://ezone.org/damaskin/ [08.06.2006].

Velmar-Janković, S. 1991. Lagum. Beograd: BIGZ.

Velmar-Janković, S. 2002. Dungeon, prev. C. Hawkesworth. Beograd: Dereta. 


\section{SUMMARY}

\section{TRANSLATION EQUIVALENCE AT THE LEVEL OF LEXICAL PATTERNS}

The paper presents the examination of collocational equivalence in a sample of published English translations of Serbian literary texts. The collocations in the source and target parallel sentences are studied with regard to equivalence of content and the translators' observance of lexical patterning factors in the target language (TL). Target text (TT) collocations are considered equivalent to the relevant source text (ST) collocations if they transfer the content and comply with the collocability parameters of the combined TL lexemes, which include collocational restrictions, collocational ranges and semantic prosody. Precisely, the equivalence rests not only on the faithfulness of meaning, but also on the compatibility of the lexemes combined in the TT, based on (a) semantic features of the lexemes, (b) immediate context and (c) prosodic restraints, which arise from their preferences in combining with other lexemes of positive or negative meaning.

KEYWORDS: lexeme, collocation, equivalence, congruence, polysemy, collocational range, semantic prosody.

(Originalan naučni rad primljen 04.01.2011; ispravljen 09.09.2011; prihvaćen 01.09.2011) 